\title{
The Bond-Energy Bond-Order (BEBO) Model of Chemisorption
}

\author{
W. H. Weinberg
}

Division of Chemistry and Chemical Engineering, California Institute of Technology, Pasadena, California 91109

(Received 31 July 1972; in final form 13 September 1972)

\begin{abstract}
The bond-energy bond-order (BEBO) model of chemisorption allows an estimate to be made of the interaction energy between a gaseous specie and a solid surface as a function of either bond length or bond order, i.e., the length or order of either the gas-surface bond being formed or the bond of the gaseous molecule being broken. The relationship between bond energy and either bond length or bond order is deduced from spectroscopic correlations for gaseous molecules, and a linear relationship between bond energy and bond order is assumed for the surface-adsorbate interaction. The geometry of the surface orbitals is taken to be that predicted by the crystal field model. The model allows a prediction of several relevant quantities in gas-surface interactions, namely: (1) binding energies for molecular adsorbed species, (2) binding energies for atomically adsorbed species, (3) activation energies to chemisorption, and (4) activation energies to dissociative chemisorption. The model is illustrated for the adsorption of $\mathrm{H}_{2}, \mathrm{CO}$, $\mathrm{NO}$ and $\mathrm{O}_{2}$ on $\mathrm{Pt}, \mathrm{W}$ and $\mathrm{Ni}$ surfaces.
\end{abstract}

\section{Introduction}

Although a reliable quantum mechanical theory of covalent chemisorption on metal surfaces does not presently exist, it would nevertheless be highly desirable to be alble to make predictions concerning the way in which adsorbates interact chemically with solid surfaces. Evidently what is needed is an empirical model description of chemisorption-the formation of chemical bonds between a gaseous specie and a solid surfacein the spirit of the empiricism used by Pauling to describe molecular bonding over forty years ago. Such an approach has recently been formulated in which the variation of bond energy in chemical bonds being broken or formed is given by spectroscopic correlations for gaseous species, and a linear relationship is assumed for the variation of bond energy with bond order for surface-gas bonds. ${ }^{1-5}$ Electrons, or equivalently chemical bonds, are conserved and the geometry of the surface orbitals is taken to be that predicted by crystal field theory. ${ }^{7}$

This model has been applied to the adsorption of $\mathrm{H}_{2}$. on (111) $\mathrm{Pt}^{1} \mathrm{O}_{2}, \mathrm{CO}$, and $\mathrm{CO}_{2}$ on (111) $\mathrm{Pt}$ and $\mathrm{Ni} ;{ }^{2}$ $\mathrm{N}_{2}, \mathrm{NO}$, and $\mathrm{N}_{2} \mathrm{O}$ on (111) $\mathrm{Pt}^{3}$ and $\mathrm{Ni}$; and $\mathrm{O}$. on both clean and carbon contaminated (111) $\mathrm{Pt}^{4}{ }^{4}$ The model can also be applied to simple surface reactions, and in particular has been used to describe the reaction of $\mathrm{O}_{2}$ and $\mathrm{CO}, \mathrm{NO}$ and $\mathrm{CO}$, and $\mathrm{H}_{2}$ and $\mathrm{O}_{2}$ on (111) $\mathrm{Pt},{ }^{5}$ as well as the hydrogenation of $\mathrm{C}_{2} \mathrm{H}_{4}$ and the nucleation of graphitic carbon on (111) Pt and Ni. ${ }^{6}$ In this communication the BEBO model is described, and selected results for the adsorption of $\mathrm{H}_{2}, \mathrm{O}_{3}, \mathrm{CO}$, and $\mathrm{NO}$ on $\mathrm{Pt}, \mathrm{Ni}$, and $\mathrm{W}$ surfaces are presented.

Attention will be focussed on the (111) crystallographic orientation of $\mathrm{Pt}$ and $\mathrm{Ni}$ (hoth face-centered cubic metals) and a brief word will be mentioned concerning the (100) crystil face of $W$ (a body-centered cubic metal). The geometries of (111) fcc (face-centered cubic) metals and (100) bec (body-centered cubic) metals are shown in Fig. 1. There are two distinct bonding sites on the (111) foc plane and three nonequivalent bonding sites on the (100) bcc plane. On the (111) fcc plane these sites are termed the $e_{0}$ and $t_{\text {. }}$ sites in accordance with the symmetry of the $d$ orbitals from which they derive, ${ }^{1-6}$ and on the (100) bec plane the sites are termed the $A, B$ and $C$ sites. Thus, it is seen that germane features of the crystal field theory (i.e., surface orbital geometry) introduces into the model the possibility of multiple binding states of an adsorbate on a given surface plane. Such multiple binding states are a well estalblished experimental fact.

In order to calculate the electron occupancy of the surface orbitals, it is assumed that the available bonding electrons are equally divided (in a time-averaged sense) over all the pertinent orbitals ( $d, p$, or $s$ orbitals). The

Frgure 1(a). The (111) plane of an fec metal showing the $e_{g}$ and $\iota_{2 \sigma}$ adsorption sites. (b) The (100) plane of a bcc netal showing the $A, B$ and $C$ adsorption sites.
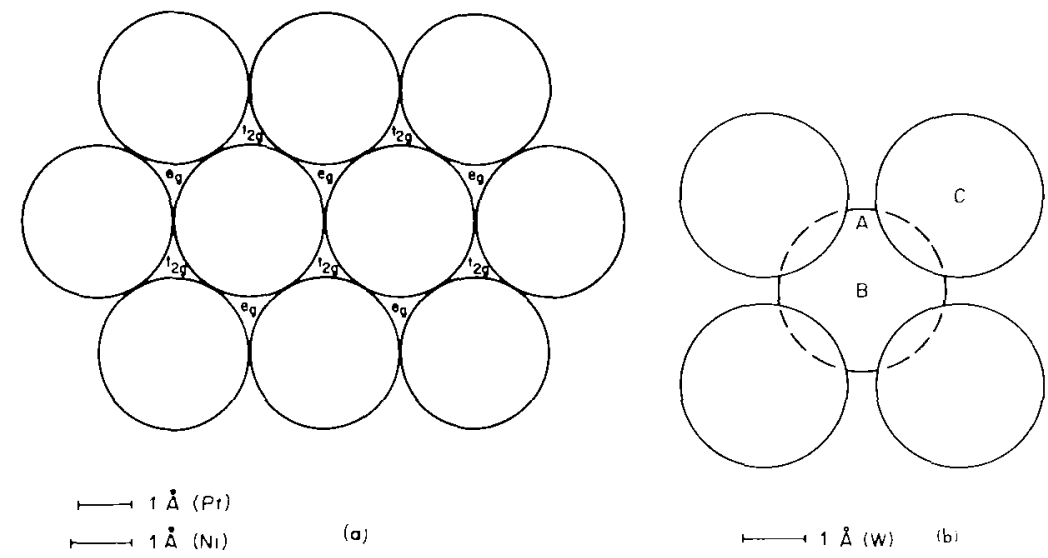


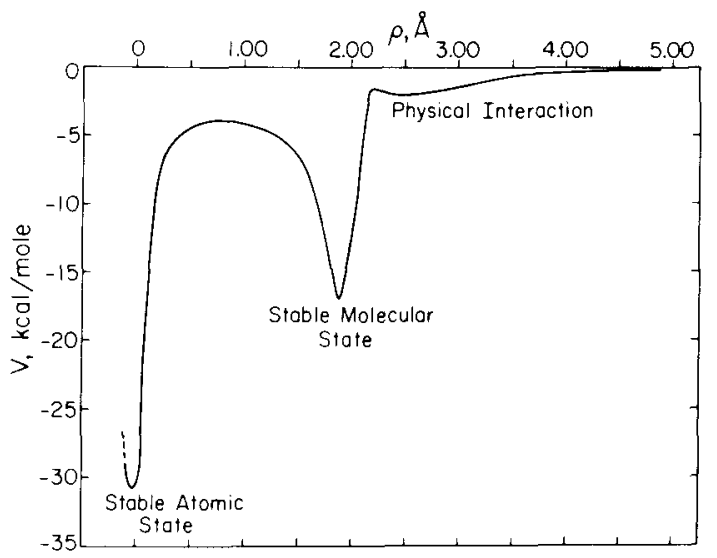

Figure 2. The interaction energy of $\mathrm{H}_{2}$ with $\mathrm{Pt}$ (111) as a function of reaction coordinate which is set equal to zero at the minimum of the stable atomic well

electronic configuration used is that predicted by the Engel-Brewer rules, ${ }^{8}$ namely $d^{n-1} s$ for bcc metals and $d^{n-3} s p^{2}$ for fcc metals where $n$ is the number of outer shell electrons. Thus, the electronic configuration of $\mathrm{Pt}$ and $\mathrm{W}$ is expected to be $5 d^{7} 6 s p^{2}$ and $5 d^{5} 6 s$, respectively.

By combining the BEBO concepts with the crystal field theory (the latter gives the surface orbital geometry and occupancy), it is possible to make rather detailed predictions concerning the way in which simple adsorbates interact with metal surfaces. For example, it is possible to predict in certain cases the following quantities: (1) the activation energy to adsorption, (2) the binding energy of both molecularly and dissociatively adsorbed species, and (3) the activation energy to dissociative chemisorption.

\section{BEBO Model}

The philosophy of how the BEBO model is used in connection with describing the chemical interaction of gases with surfaces has been given in the Introduction. A more detailed description of the model will now be presented. When a diatomic gas molecule interacts with a surface, the energetics involved may be thought of in terms of a Born-Haber cycle. For example, consider that the molecule $A B$ is adsorbed on a metal surface $M$. The binding energy $V$ of an adstate (in the most general case, a molecular state) is equal to the following contributions: (1) the dissociation energy of $A B, D_{A B}$, (2) the binding energies of both $A$ and $B$ to the surface, $E_{M-A}$ and $E_{M-B}$, and (3) the energy in the $A B$ molecule while in the adstate on the surface, $E_{\mathrm{Sur}, A B}$. This cycle may be written in the following way (assuming the zero of energy is the infinitely separated gas and surface)

$$
V=D_{A B}-E_{M-A}-E_{M-B}-E_{\mathrm{sur}, A B} .
$$

The dissociation energy of the $A B$ molecule is a known quantity; and the energies of the gas-metal bonds are assumed to obey the following relationship,

$$
E_{M-i}=E_{M-i, s} n_{M-i},
$$

where $E_{M-i, s}$ is the single order bond energy between the two chemical species $M$ and $i$, and $n_{M-i}$ is the bond order between $M$ and $i$. The single order bond energy is of ten available in the literature ${ }^{9,10}$ or may be estimated empirically. ${ }^{1-6}$ The energy in the $A B$ bond while adsorbed on the surface may be calculated from an equation of the form ${ }^{11}$

$$
E_{A B}=E_{A B, s} n_{A B}{ }^{p},
$$

where $E_{A B, s}$ is the single order bond energy in the $A B$ molecule, $n_{A B}$ is the bond order of the $A B$ molecule, and $p$ is an empirical exponent which normally has a value very close to unity. Alternatively, spectroscopic correlations relating the energy in the $A B$ bond to its bond order may be used."

When applying the $\mathrm{BEBO}$ model to actual gassurface interactions, the knowledge of the surface orbital geometry derived from the crystal field model of a surface is used. This can lead to interesting results, and in particular the possibility of multiple bonding states of a gas even on a low-index plane of a metal single crystal. The model will now be illustrated for the case of several specific examples.

\section{Calculated Results}

\section{A. Hydrogen Adsorption on Platinum (111) and Tungsten (100)}

\section{1. $I H_{2}+P t(111)$}

The $e_{g}$ and $t_{2 \vartheta}$ sites on a Pt (111) surface are not equivalent. The triad of orbitals comprising the $e_{g}$ site makes an angle of $35^{\circ} 16^{\prime}$ with the surface plane while the triad of orbitals comprising the $t_{2 g}$ site makes an angle of $54^{\circ} 44^{\prime}$. This geometry thus favors the $t_{2 g}$ sites as possible molecular sites for $\mathrm{H}_{2}$ and the $e_{g}$ sites as possible atomic sites for the hydrogen adsorbate. ${ }^{1}$ In fact, $\mathrm{H}_{2}$ can interact with two of the three individual $t_{2 g}$ orbitals of the $t_{2 g}$ site. The $\mathrm{H}-\mathrm{H}$ bond is stretched (an endothermic process) while the $\mathrm{Pt}-\mathrm{H}$ bonds are formed (an exothermic process). This continues until either of two events occur: (1) the electrons available in the surface orbitals are depleted, or (2) the hard sphere radius of the $\mathrm{Pt}-\mathrm{H}$ complex is reached (1.685 $\AA$ ). The occupancy of the $t_{2 g}$ surface orbitals of platinum is 0.6 electron. ${ }^{1}$ After a molecular state is formed, dissociation of the $\mathrm{H}_{2}$ may occur via surface diffusion of the two atoms to the atomic bonding $e_{\theta}$ sites. Since the geometry of these interactions is known (both that of the surface orbitals and molecular hydrogen), the potential energy of interaction of $\mathrm{H}_{2}$ with a $\mathrm{Pt}$ (111) surface may be calculated as a function of "reaction (i.e., adsorption) coordinate," $\rho$.

For this purpose Eq. (1) is rewritten as

$$
V=D_{\mathrm{H}_{2}}-2 E_{\mathrm{Pt}-\mathrm{H}}-E_{\mathrm{Sur}_{1} \mathrm{H}_{2}} .
$$

The chemical interaction commences when the $\mathrm{H}-\mathrm{H}$ bond begins to stretch and the two $\mathrm{Pt}-\mathrm{H}$ bonds begin to form. The energy in the $\mathrm{H}_{2}$ molecule is known from the bond energy-bond length $(\mathrm{BEBL})^{1,11}$ correlation, i.e., 
the potential energy of interaction is calculated as a function of bond length or reaction coordinate. The term $E_{P \mathrm{t}-\mathrm{H}}$ of Eq. (4) is calculated in the following way. The bond order in the $\mathrm{H}_{2}$ on the surface is calculated from the equation (with all energy units in kcal/ mole)

$$
E_{\mathrm{H}_{2}}=103.2 n_{\mathrm{H}_{2}}{ }^{1.041} \text {, }
$$

since $E_{\mathrm{H}_{2}}$ is known as a function of $\rho$. From conservation of chemical bonds, it follows that

$$
n_{\mathrm{Pt}-\mathrm{H}}=1-n_{\mathrm{H}_{2}}
$$

and thus $E_{\mathrm{Pt}-\mathrm{H}}$ may be calculated from the following equation

$$
E_{\mathrm{Pt}-\mathrm{H}}=67 n_{\mathrm{Pt}-\mathrm{H}},
$$

since $E_{\mathrm{Pt}-\mathrm{H}, s}$ is known to be $67 \mathrm{kcal} /$ mole. $^{1}$ The dissociation energy of $\mathrm{H}_{2}, D_{\mathrm{H}_{2}}$, is $103.2 \mathrm{kcal} /$ mole. This allows the interaction energy $V(\rho)$ to be calculated, and the result is shown in Fig. 2. The physical interaction well [calculated assuming a Lennard-Jones (3-9) potential] is shown for completeness together with both the molecular and atomic chemical wells. The former has a binding energy of $17 \mathrm{kcal} / \mathrm{mole}$, while the latter has a binding energy of $31 \mathrm{kcal} / \mathrm{mole}$. The molecular well occurs when $n_{\mathrm{Pt}-\mathrm{H}}=0.6$, and the $\mathrm{Pt}-\mathrm{H}$ bond length is $1.81 \AA$ as opposed to the hard sphere of $1.68 \AA$. No activation energy relative to the energy zero is predicted for the adsorption or the dissociation of $\mathrm{H}_{2}$ by Pt (111).

\section{2. $H_{2}+W(100)$}

A general reaction coordinate picture of the $\mathrm{H}_{2}-\mathrm{W}$ (100) interaction may be calculated just as was done for the case of $\mathrm{H}_{2}+\mathrm{Pt}$ (111) given above. ${ }^{12}$ From orbital overlap considerations it would be excepted that a molecular interaction would occur on the $A$ sites of Fig. 1(b), whereas atomic adsorption would occur on the $B$ sites (and perhaps on the $C$ sites at quite high coverages). Since the surface orbital occupancy is greater for $\mathrm{W}$ than $\mathrm{Pt}$ the molecularly adsorbed state at the $A$ sites occurs at the hard sphere radius of the $\mathrm{W}-\mathrm{H}$ complex, namely $1.66 \AA$. At this point the $\mathrm{H}_{2}$ bond length is $1.23 \AA$, and the $\mathrm{H}_{2}$ bond order may be calcu-

FIgURE 3. BEBO correlation for $\mathrm{O}_{2}, \mathrm{CO}$, and $\mathrm{NO}$ bonds.

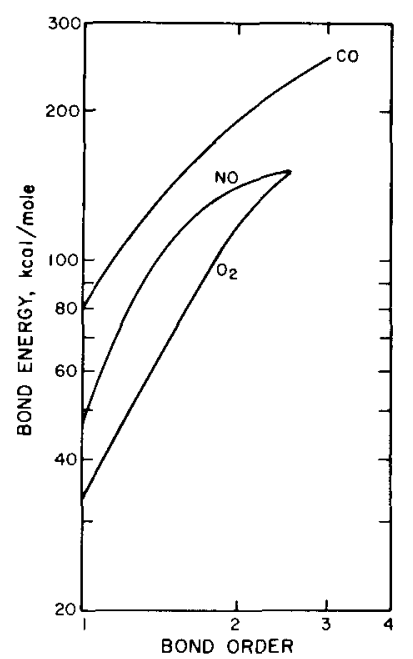

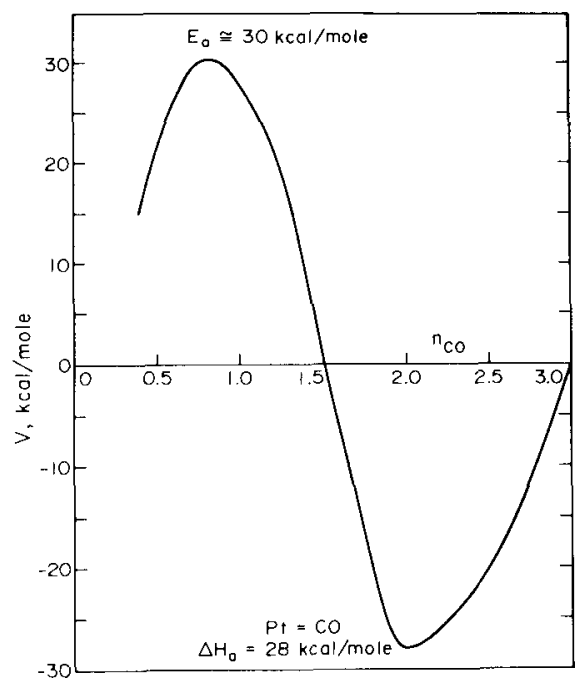

Figure 4. Calculated interaction energy for $\mathrm{CO}$ adsorption on Pt (111).

lated from the Pauling relationship ${ }^{13}$ for $\mathrm{H}_{2}$,

$$
R=R_{s}-0.26 \ln n_{\mathrm{H}_{2}}
$$

and in the present case $R=1.23 \AA$ and $R_{s}$, the single order bond length, is $0.74 \AA$. Thus the bond order for $\mathrm{H}_{2}$ adsorbed in the molecular $A$ sites is 0.15. Equations (4) and (5) may now be used together with the analogue to Eq. (7) for $\mathrm{H}_{2}-\mathrm{W}$ (100) interactions, namely ${ }^{12}$

$$
E_{\mathrm{W}-\mathrm{H}}=67.7 n_{\mathrm{W}-\mathrm{H}},
$$

to give both the molecular binding energy of $\mathrm{H}_{2}$ on (100) W $\left(n_{\mathrm{H}_{2}}=0.15\right.$ and $\left.n_{\mathrm{W}-\mathrm{H}}=0.85\right)$ and also the atomic binding energy $\left(n_{\mathrm{H}_{2}}=0, n_{\mathrm{W}-\mathrm{H}}=1\right)$. The binding energies for the molecular state and atomic state are calculated to be 26.2 and $32.2 \mathrm{kcal} /$ mole, respectively.

\section{B. Carbon Monoxide Adsorption on Platinum}

Due to orbital overlap considerations, $\mathrm{CO}$ is expected to adsorb on Pt (111) at the $e_{g}$ sites; and elementary quantum chemical considerations ${ }^{14,15}$ coupled with empirical infrared spectroscopy results ${ }^{16}$ indicate the interaction is between the $\mathrm{Pt}$ and the $\mathrm{C}$ atom of the $\mathrm{CO}$ molecule. The potential energy of interaction may be written in analogy with Eq. (1) as

$$
V(n)=D_{\mathrm{CO}}-E_{\mathrm{Pt}-\mathrm{CO}}-E_{\mathrm{Sur}, \mathrm{Co}},
$$

where $D_{\mathrm{CO}}=256 \mathrm{kcal} / \mathrm{mole}$ and $E_{\mathrm{Sur}, \mathrm{co}}$ may be obtained as a function of $n_{\mathrm{CO}}$ (and equivalently as a function of $n_{\mathrm{Pt}-\mathrm{Co}}$ through the appropriate bond conservation relationships ${ }^{2}$ ) from the spectroscopic correlation shown in Fig. 3. The $\mathrm{Pt}-\mathrm{CO}$ bond energy is given by

$$
E_{\mathrm{Pt} \sim \mathrm{CO}}=46 n_{\mathrm{Pt}-\mathrm{Co}}
$$

since the single bond energy of $\mathrm{Pt}-\mathrm{CO}$ is $46 \mathrm{kcal} / \mathrm{mole}^{2}$

The calculated interaction energy of $\mathrm{CO}$ with $\mathrm{Pt}$ (111) is shown in Fig. 4. There is a stable molecularly adsorbed state with a binding energy of $28 \mathrm{kcal} /$ mole at which point $n_{\mathrm{CO}}=n_{\mathrm{Pt}-\mathrm{CO}}=2.00$. The calculated acti- 


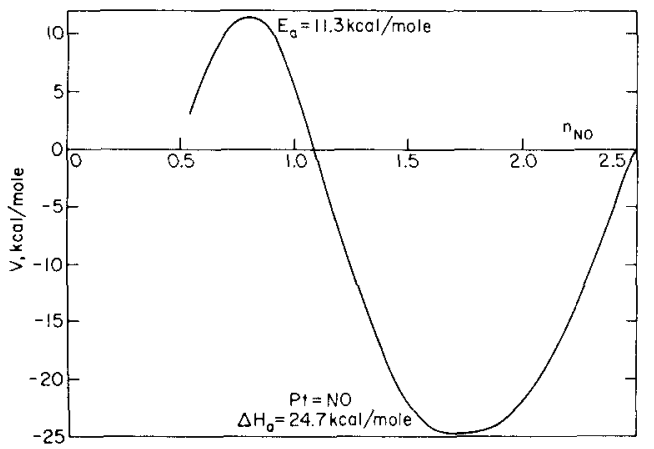

Figure 5: Calculated interaction energy for NO adsorption on Pt (11).

vation energy to dissociation is $\sim 30 \mathrm{kcal} /$ mole. The calculated molecular state is a result of the BEBO relation for $\mathrm{CO}$ (Fig. 3), and not, for example, a result of electron depletion of surface orbitals. Thus, it would be expected that on relatively smooth low index planes of $\mathrm{Pt}$ the binding energy should be rather constant, approximately $28 \mathrm{kcal} /$ mole. On rougher surfaces of $\mathrm{Pt}$ it is possible simultaneous interaction of both the $\mathrm{C}$ and $\mathrm{O}$ atoms in the $\mathrm{CO}$ molecule with surface orbitals could lead to dissociative adsorption with an activation energy much less than $30 \mathrm{kcal} /$ mole. Further details concerning the $\mathrm{CO}-\mathrm{Pt}$ (111) interaction may be found in Reference 2.

\section{Nitric Oxide Adsorption on Platinum (111)}

The interaction between NO and $\mathrm{Pt}(111)$ is expected to be very similar to that of $\mathrm{CO}$, namely adsorption through the $\mathrm{N}$ atom at an $e_{0}$ site on the Pt surface. ${ }^{3}$ Equation (1) may be written in the following form for the $\mathrm{NO}-\mathrm{Pt}$ interaction

$$
V(n)=D_{\mathrm{NO}}-E_{\mathrm{Pt}-\mathrm{NO}}-E_{\mathrm{Sur}, \mathrm{NO}},
$$

where $D_{\mathrm{NO}}=151 \mathrm{kcal} /$ mole and $\mathrm{E}_{\mathrm{Sur}}$, No is given as a function of $n_{\mathrm{N}} \mathrm{O}$ in Fig. 3. The bond energy between a $\mathrm{Pt}$ atom and an NO molecule is given by ${ }^{17}$

$$
E_{\mathrm{Pt}-\mathrm{NO}}=32 n_{\mathrm{Pt}-\mathrm{NO}} \text {, }
$$

with the single order bond energy of $\mathrm{Pt}-\mathrm{NO}$ given by $32 \mathrm{kcal} / \mathrm{mole}$ and with elementary bond conservation relations relating $n_{\mathrm{No}}$ to $n_{\mathrm{Pt}-\mathrm{NO}} .^{3,17}$

The interaction energy $V\left(n_{\mathrm{N}}\right)$ may be calculated using Eqs. (12) and (13) together with Fig. 3, and the result is shown in Fig. 5. There is a molecularly adsorbed

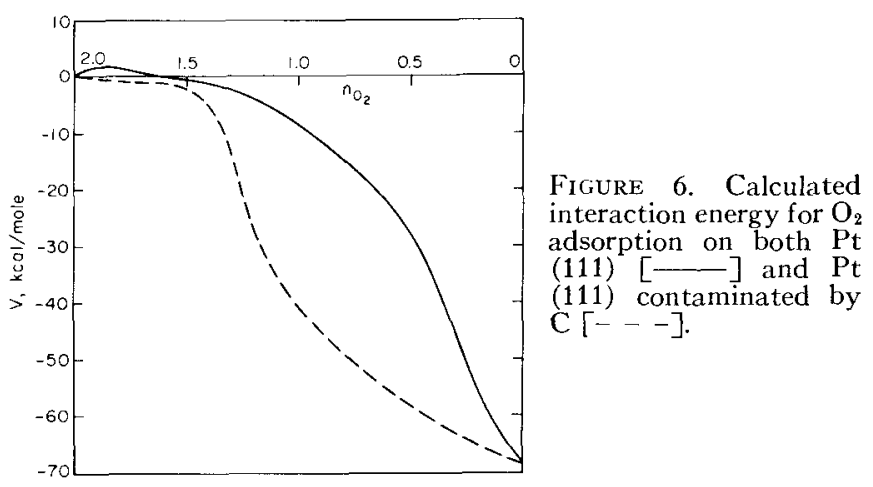

state of NO on Pt (111) with a binding energy of 24.7 $\mathrm{kcal} /$ mole which occurs when $n_{\mathrm{Pt}-\mathrm{NO}}=1.5$ and $n_{\mathrm{NO}}$ $=1.75$. The calculated activation energy to dissociation of the NO molecule on the Pt surface is $11.3 \mathrm{kcal} /$ mole (relative to gaseous $\mathrm{NO}$ ), and this energy barrier occurs at $n_{\mathrm{NO}}=0.775$. The calculations indicate no activation energy for adsorption into the molecular state.

D. Oxygen Adsorption on Platinum (111), Nickel (111), and a Platinum (111) Surface with Adsorbed Carbon

1. $O_{2}+P t(111)$

The initial interaction of $\mathrm{O}_{2}$ with $\mathrm{Pt}(111)$ is also expected to occur through an $e_{a}$ site for overlap reasons. ${ }^{2,4}$ The potential energy of interaction is given by

$$
V(n)=D_{\mathrm{O}_{2}}-E_{\mathrm{P}_{\mathrm{t}-\mathrm{O}_{2}}}-E_{\mathrm{Sur}}, \mathrm{O}_{2},
$$

where $D_{\mathrm{O}_{2}}=118 \mathrm{kcal} / \mathrm{mole}$ and $E_{\mathrm{Sur}, \mathrm{O}_{2}}$ is given in Fig. 3 as a function of $n_{\mathrm{O}_{2}}$. The bond energy between $\mathrm{Pt}$ and $\mathrm{O}_{2}$ is given by ${ }^{2,4}$

$$
E_{\mathrm{Pt}-\mathrm{O}_{2}}=46.6 n_{\mathrm{Pt}-\mathrm{O}_{2}} \text {, }
$$

since the single order $\mathrm{Pt}-\mathrm{O}$ bond energy is $46.6 \mathrm{kcal} /$ mole. ${ }^{2,4,18} \mathrm{~A}$ plot of the interaction energy $V$ as a function of bond order in the $\mathrm{O}_{2}$ molecule is shown in Fig. 6 . There is a calculated activation energy to adsorption of $\sim 3 \mathrm{kcal} / \mathrm{mole}$, and the dissociative heat of adsorption is predicted to be $68 \mathrm{kcal} /$ mole. The $\mathrm{BEBO}$ model does not predict the existence of a stable molecularly adsorbed state.

\section{2. $\mathrm{O}_{2}+\mathrm{Ni}(111)$}

The interaction of $\mathrm{O}_{2}$ with $\mathrm{Ni}$ (111) may be treated in an analogous way to that of Pt(111) given above. ${ }^{2}$ The important differences are that the lattice spacing is smaller on $\mathrm{Ni}$ as compared with $\mathrm{Pt}$ (which modifies the relative positions of the adsorption sites on the surface), and the $\mathrm{Ni}-\mathrm{O}$ bond energy is given by the following equation [the analogue of Eq. (15)], ,,18

$$
E_{\mathrm{Ni}-\mathrm{O}_{2}}=58 n_{\mathrm{Ni}-\mathrm{O}_{2}}
$$

since the single order bond energy of $\mathrm{Ni}-\mathrm{O}$ is $58 \mathrm{kcal} /$ mole. The calculated interaction energy for $\mathrm{O}_{2}$ and $\mathrm{Ni}$ (111) is different from that for $\mathrm{O}_{2}$ and $\mathrm{Pt}(111)$ in the following ways: (1) There is no predicted activation energy to adsorption on $\mathrm{Ni}$; and (2) the calculated heat of dissociative chemisorption is greater, approximately $114 \mathrm{kcal} / \mathrm{mole}$. A similarity in the two results is that the BEBO model predicts no stable molecularly adsorbed state of $\mathrm{O}_{2}$ on $\mathrm{Ni}(111)$.

\section{3. $\mathrm{O}_{2}+(111) \mathrm{PtC}$}

The BEBO model can also be used to predict the chemisorption properties of $\mathrm{O}_{2}$ on a carbon contaminated Pt (111) surface. ${ }^{4}$ The $\mathrm{O}_{2}$ initially interacts with the free valence of the adsorbed $\mathrm{C}$ atom, with the final 
TABLE I. Comparison of BEBO predictions with experimental data.

\begin{tabular}{|c|c|c|c|c|c|c|c|c|}
\hline \multirow[b]{2}{*}{ Gas-Surface } & \multicolumn{2}{|c|}{ Ea, ads., kcal $/ \mathrm{mole}$} & \multicolumn{2}{|c|}{$\begin{array}{c}\text { Molecular } \Delta H a, \\
\mathrm{kcal} / \mathrm{mole}\end{array}$} & \multicolumn{2}{|c|}{$\mathrm{Ea}$, dis., $\mathrm{kcal} / \mathrm{mole}$} & \multicolumn{2}{|c|}{$\begin{array}{c}\text { Dissociative } \Delta H a, \\
\mathrm{kcal} / \mathrm{mole}\end{array}$} \\
\hline & Calculated & Experimental & Calculated & Experimental & Calculated & Experimental & Calculated & Experimental \\
\hline $\begin{array}{l}\mathrm{H}_{2} / \mathrm{Pt}(111) \\
\mathrm{H}_{2} / \mathrm{W}(100)\end{array}$ & $\begin{array}{l}0 \\
0\end{array}$ & $\sim 0^{\mathrm{a}}$ & $\begin{array}{l}17 \\
26.2\end{array}$ & $\begin{array}{l}\sim 18^{\mathrm{a}} \\
26.3^{\mathrm{b}} \\
25.2^{\mathrm{c}}\end{array}$ & $\begin{array}{l}0 \\
0\end{array}$ & $\begin{array}{l}\sim 0^{\mathrm{a}} \\
\sim 0^{\mathrm{b}, \mathrm{c}}\end{array}$ & $\begin{array}{l}31 \\
32.2\end{array}$ & $\begin{array}{l}\sim 31^{\mathrm{a}} \\
\quad 32.3^{\mathrm{b}, \mathrm{c}}\end{array}$ \\
\hline $\mathrm{CO} / \mathrm{Pt}(111)$ & 0 & $\sim 0^{\mathrm{d}, \mathrm{e}, \mathrm{f}}$ & 28 & $\sim 28^{\mathrm{d}, \mathrm{e}, \mathrm{f}}$ & $\sim 30$ & $\begin{array}{l}\text { "large"d,e } \\
>10^{f}\end{array}$ & $\cdots$ & $\cdots$ \\
\hline $\begin{array}{l}\mathrm{NO} / \mathrm{Pt}(111) \\
\mathrm{O}_{2} / \mathrm{Pt}(111) \\
\mathrm{O}_{2} / \mathrm{Ni}(111) \\
\mathrm{O}_{2} / \mathrm{PtC}\end{array}$ & $\begin{array}{r}0 \\
\sim 3 \\
0 \\
0\end{array}$ & $\begin{array}{l}\sim 0^{\mathrm{g}} \\
\sim 3^{\mathrm{d}, \mathrm{e}, \mathrm{h}, \mathrm{i}, \mathrm{j}} \\
\sim 0^{\mathrm{k}} \\
\sim 0^{\mathrm{i}}\end{array}$ & $\begin{array}{l}24.7 \\
\cdots \\
\cdots \\
\cdots\end{array}$ & $\begin{array}{r}\sim 25^{\mathrm{g}} \\
\ldots \\
\ldots \\
\ldots\end{array}$ & $\begin{array}{c}11.3 \\
0 \\
0 \\
0\end{array}$ & $\begin{array}{l}\sim 12 \mathrm{~g} \\
\sim 0^{\mathrm{h}, \mathrm{i}, \mathrm{j}, \mathrm{k}} \\
\sim 0^{\mathrm{k}} \\
\sim 0^{\mathrm{i}}\end{array}$ & $\begin{array}{r}\ldots \\
68 \\
114 \\
68\end{array}$ & $\begin{array}{c}\cdots \\
64^{\mathrm{k}} \\
107^{\mathrm{k}} \\
\mathrm{ND}^{1}\end{array}$ \\
\hline $\begin{array}{l}\text { a Reference } \\
\text { b Reference } \\
\text { c Reference }\end{array}$ & & $\begin{array}{l}{ }^{d} \mathrm{R} \\
\text { e Rf } \\
{ }^{\mathrm{f}} \mathrm{Re}\end{array}$ & $\begin{array}{l}\text { rence } 29 . \\
\text { ence } 30 . \\
\text { ence } 31 .\end{array}$ & & $\begin{array}{l}\text { a Reference } \\
\text { h Reference } \\
\text { i Reference }\end{array}$ & & $\begin{array}{l}j \mathrm{R} \\
\mathrm{k} R \\
{ }^{1} \mathrm{~N}\end{array}$ & $\begin{array}{l}\text { ference } 32 \\
\text { ference } 33 \\
\equiv \text { No data. }\end{array}$ \\
\hline
\end{tabular}

adstate being an $\mathrm{O}$ atom bound to a $\mathrm{Pt}$ site and a $\mathrm{CO}$ molecule also bound to a Pt atom. The interaction energy may be written as

$$
V(n)=D_{\mathrm{o}_{2}}-E_{\mathrm{PtC}-\mathrm{O}_{2}}-E_{\mathrm{Sur}}, \mathrm{o}_{2}
$$

and the $\mathrm{BEBO}$ relationships (Fig. 3) for both $\mathrm{CO}$ and $O O$ bonds are used together with equations (11) and (15). The number of bonding electrons, i.e., the number of chemical bonds, is conserved in the usual fashion. The calculated interaction energy is shown in Fig. 6. The BEBO model predicts no activation energy to adsorption, no stable state of molecularly adsorbed $\mathrm{O}_{2}$, and a dissociative heat of adsorption of $68 \mathrm{kcal} / \mathrm{mole}(\mathrm{Pt}=\mathrm{CO}$ $+P t=0)$. That is fortuitously the same value for the dissociative heat of adsorption of $\mathrm{O}_{2}$ on clean $\mathrm{Pt}$ (111).

\section{Summary}

The BEBO model has been described and applied to the chemisorption of several atomic molecules on various surfaces, i.e., $\mathrm{H}_{2}$ on $\mathrm{Pt}(111)$ and $\mathrm{W}(100)$, CO on $\mathrm{Pt}$ (111), $\mathrm{NO}$ on $\mathrm{Pt}$ (111), and $\mathrm{O}_{2}$ on $\mathrm{Pt}$ (111), $\mathrm{Ni}$ (111) and a $\mathrm{Pt}$ (111) surface contaminated by carbon. The calculated results are shown in Table I together with a comparison with relevant experimental results. It is clear that the BEBO model describes very well these gas-surface interactions; and it has also been used to successfully elucidate the chemisorption of several other molecules on various metal surfaces, ${ }^{1-4}$ and to predict the energetics of several heterogeneously catalyzed surface reactions. ${ }^{5,6}$

Perhaps the greatest uncertainties in the $\mathrm{BEBO}$ model are the following: (1) The single order bond energy to be used in calculating the gas-surface bond energy, i.e., $E_{M-i, s}$ of Eq. (2); (2) the appropriate $\mathrm{BEBO}$ relationship for the surface-gas bonds, i.e., the exponent of the bond order in Eq. (2) may not be exactly unity; (3) the geometry of the surface orbitals may not be that predicted by the crystal field model; and (4) the electronic structure of the surface orbitals may not be precisely that predicted by the EngelBrewer rules. It is probable that the uncertainty in $E_{M-i, s}$ leads to the greatest source of error in the BEBO calculations. It has been argued previously that the surface-gas bond energy should be very nearly linear with bond order. ${ }^{1-3}$ The success of the model especially for the case of $\mathrm{H}_{2}$ adsorption strongly suggests that the surface orbitals (at least in the presence of an adsorbing gas) have approximately the geometry as in the bulk solid and the Engel-Brewer rules have been shown to be quite reliable in predicting the electronic structure of both metals and alloys. ${ }^{7,19}$ In the most unfavorable case a value of $E_{M-i, s}$ may have to be derived by fitting empirical chemisorption data, but generally its value can be deduced either from available thermochemical data (e.g., heats of sublimation or heats of formation) or empirical mixing rules. ${ }^{1-3}$

The BEBO model implicitly implies the formation of a localized "surface molecule" as a result of chemisorption. This is a very attractive concept which has recently been given a theoretical foundation. ${ }^{15,20,21}$ Experimental evidence for this proposition is derived from the studies of Sachtler et al. ${ }^{20,21}$ on $\mathrm{Cu}-\mathrm{Ni}$ alloys who have shown that an adsorbing gas molecule actually can discriminate between a surface $\mathrm{Ni}$ and $\mathrm{Cu}$ atom, i.e., the chemisorption is evidently not governed by collective properties such as the structure of the $d$-band or the position of the Fermi energy. In addition, Boudart ${ }^{22}$ has shown that the chemisorption properties of gas molecules are identical on both very dispersed metal particles whose diameter is only $\sim 10 \AA$ (i.e., the particles are essentially totally surface) as well as on metal conglomerates whose diameter is on the order of hundreds of Ångstroms (i.e., particles with a small surface-to-volume ratio). If collective electronic properties of the metal are important, differences in the experimental results for these two radically different surfaces would be expected, but none were noted. These results tend to support the BEBO approach.

It is useful to briefly compare the $\mathrm{BEBO}$ method with previous thermochemical calculations aimed at estimating initial heats of adsorption. The latter approaches have generally been confined to the interaction of $\mathrm{H}_{2}$ with metal surfaces ${ }^{23}$; however, Higuchi et al. have also considered the adsorption of $\mathrm{O}_{2}, \mathrm{~N}_{2}$, and $\mathrm{CO}$ on various transition metals. ${ }^{24}$ Eley has assumed that the metal-hydrogen bound energy is given by (with 
energy units in $\mathrm{kcal} / \mathrm{mole}$ )

$$
E_{M-\mathrm{H}, s}=\frac{1}{2}\left(D_{M M}+D_{\mathrm{H}_{2}}\right)+23.06\left(\chi_{M}-\chi_{\mathrm{H}}\right)^{2}
$$

where $D_{M M}$ is the metal-metal single order bond energy, $D_{\mathrm{H}_{2}}$ is the dissociation energy of $\mathrm{H}_{2}$ and, $\chi_{M}$ and $\chi_{\mathrm{H}}$ are the electronegativities of the $M$ and $\mathrm{H}$ atoms respectively. ${ }^{23}$ A value of $D_{M M}$ is obtained by multiplying the bulk heat of sublimation of the metal by a factor which accounts for the multiple bonding in the bulk metal; this factor is normally $\frac{1}{6}$. A value of $\chi_{M}-\chi_{\mathrm{H}}$ is obtained from experimental surface potential or work function measurements. The (dissociative) heat of adsorption of $\mathrm{H}_{2}$ on the metal surface is given by

$$
\Delta H_{a}=D_{\mathrm{H}_{2}}-2 E_{M-\mathrm{H}, s},
$$

with the value of $E_{M-\mathrm{H}, \mathrm{s}}$ obtained from Eq. (18).

The BEBO model draws on the approach of Eley, but extends it and thus renders the method considerably more powerful. This is easily recognized when one realizes that Eqs. (18) and (19) give only the dissociative heat of chemisorption. The BEBO model not only yields a value for the binding energy of the dissociated adspecie, but also gives the entire potential energy of interaction as a function of bond order. Thus activation energies to both molecular and dissociative chemisorption are obtained as well as the prediction of whether or not a stable molecular adstate exists on the surface. The BEBO model also takes account of surface geometry (anisotropic adsorption on different crystallographic orientations of the same metal), a feature lacking in the older thermochemical models. ${ }^{23}$

The application of the BEBO model to chemisorption on transition metal surfaces has been demonstrated in this communication as well as other work. ${ }^{1-4}$ It seems likely that the BEBO model can also be applied to adsorption on Group IV or III-V semiconductor surfaces where localized bonding should be important. ${ }^{25}$ The treatment is probably not amenable to highly ionic solids such as oxides or alkali halides where long range electrostatic interactions are certainly nonnegligible. The BEBO model would probably also fail at describing metallic bonding, e.g., the adsorption of metal atoms on metal substrates. An exciting application of the BEBO model is to heterogeneous surface reactions. ${ }^{5,6}$ The energetics of various simple surface reactions can be calculated, and in favorable instances a choice may be made between Rideal-Eley and Langmuir-Hinshelwood kinetics.

\section{Acknowledgment}

It is a pleasure to acknowledge the close collaboration of Professor R. P. Merrill of the Department of Chemi- cal Engineering of the University of California, Berkeley; the hospitality of Professor J. W. Linnett, F. R. S. and Dr. R. M. Lambert at the Department of Physical Chemistry of the University of Cambridge (NSF funding); and the financial support of the Division of Chemistry and Chemical Engineering of the California Institute of Technology during the course of this work.

${ }^{1}$ W. H. Weinberg and R. P. Merrill, Surface Sci. (to be published).

${ }^{2}$ W. H. Weinberg and R. P. Merrill, Surface Sci. (to be published).

${ }^{3}$ W. H. Weinberg and R. P. Merrill, Surface Sci. (to be published).

${ }^{4}$ W. H. Weinberg, R. M. Lambert, C. M. Comrie, and J. W. Linnett, Surface Sci. 30, 299 (1972).

${ }^{5}$ W. H. Weinberg and R. P. Merrill, J. Catalysis (to be published).

${ }^{6}$ W. H. Weinberg and R. P. Merrill, J. Catalysis (to be published).

${ }^{7}$ G. C. Bond, Discuss. Faraday Soc. 41, 200 (1966).

${ }^{8} \mathrm{~L}$. Brewer, in Phase Stability in Metals and Alloys, edited by $\mathrm{P}$ Rudman, J. Stringer and R. I. Jaffee, (McGraw-Hill, N. Y., 1967).

${ }^{9}$ T. L. Cottrell, The Strengths of Chemical Bonds, 2nd Ed., (Butterworths, London, 1958).

${ }^{10}$ V. I. Vedeneyev, L. V. Gurvich, V. N. Kondrat' yev, V. A. Medvedev, and Ye. L. Frankevich, Bond Energies, Ionization Potentials and Electron Affinities, (St. Martin's Press, N. Y., 1966).

${ }^{11}$ H. S. Johnstón, Gas Phase Reaction Rate Theory (Ronald Press, N. Y., 1966)

${ }^{12}$ W. H. Weinberg (unpublished)

${ }^{13}$ L. Pauling, J. Am. Chem. Soc. 69, 542 (1947).

${ }^{14} \mathrm{G}$. Blyholder, J. Phys. Chem. 68, 2772 (1964).

${ }^{15}$ T. B. Grimley, in Molecular Processes on Solid Surfaces, edited by E. Drauglis, R. D. Gretz, and R. J. Jaffee, (McGraw-Hill, N. Y., 1969), p. 299

${ }^{16}$ R. R. Ford, Adv. Catal. Relat. Subj. 21, 51 (1970).

${ }^{17}$ R. M. Lambert, C. M. Comrie, W. H. Weinberg, and J. W. Linnett, Surface Sci. (to be published).

${ }^{18}$ L. Brewer, Chem. Rev. 52, 1 (1953).

${ }^{19} \mathrm{~L}$. Brewer, Science 161, 115 (1968).

${ }^{20}$ W. M. H. Sachtler and L. L. van Reijen, J. Res. Inst. Catal. Hokkaido Univ. 10, 87 (1962).

${ }^{21}$ W. M. H. Sachtler and P. van der Plank, Surface Sci. 18, 62 (1969).

${ }^{22}$ M. Boudart, AIChE J. (Am. Inst. Chem. Eng.) 18, 465 (1972).

${ }^{23}$ G. C. Bond, Catalysis by Metals (Academic Press, London, 1962), pp. $83-85$.

${ }^{24}$ I. Higuchi, T. Ree, H. Eyring, J. Am. Chem. Soc. 79, 1330 (1957).

${ }^{25}$ J. A. Schwartz, A. Ullman and R. J. Madix, "Bond-Energy Bond-Order Model Calculations for $\mathrm{O}_{2}$ Chemisorption on $\mathrm{Ge}$ Surfaces" (to be published).

${ }^{26}$ V. A. Lampton, thesis, Chemical Engineering Department, University of California, Berkeley, 1971; Paper presented at the Pacific Coast Am. Chem. Soc. Meeting, San Francisco, October, 1972.

${ }^{27}$ P. W. Tamm and L. D. Schmidt, J. Chem. Phys. 51, 5352 (1969).

${ }^{28}$ T. E. Madey and J. T. Yates, Jr. in Structure et Properítés des Surfaces des Solids, 1970, p. 155.

${ }^{29}$ A. E. Morgan and G. A. Somorjai, Trans. Am. Crystallogr. Assoc. 4, 59 (1968).

${ }^{30}$ E. Morgan and G. A. Somorjai, J. Chem Phys. 51, 3309 (1969).

${ }^{31}$ W. H. Weinberg, R. M. Lambert, C. M. Comrie, and J. W. Linnett (unpublished results).

${ }^{32}$ W. H. Weinberg, R. M. Lambert, C. M. Comrie, and J. W. Linnett, Paper presented at the 5th International Congress on Catalysis, Palm Beach, Florida, August, 1972 (to be published by North-Holland, Amsterdam, 1973).

${ }^{33}$ D. Brennan, D. O. Hayward and B. M. W. Trapnell, Proc. R. Soc. A 256, 81 (1960). 